twenty-six years, of a machine for stitching leather harness brought him the offer of a post as a draughtsman in the firm of Fairbanks, Bancroft and Co., of Providence, R.I., and in 1847 the name of this concern was altered to Corliss, Nightingale and Co., with Corliss at its head. Corliss will always be remembered for his invention of the 'Corliss' valve gear for steam-engines, in connexion with which he took out many patents, the first being secured in 1849. His engines gradually became known for their economy in steam consumption and their regular turning movement. A Corliss engine exhibited at the Paris Exhibition of 1867 took the highest prize, and out of 400 engines exhibited at Vienna in 1873 the majority were of the Corliss type. His most famous engine was that constructed for the Machinery Hall of the Centennial Exhibition at Philadelphia of 1876 which was set in motion at the opening by Emperor Dom Pedro II of Brazil. This engine had two cylinders $40 \mathrm{in}$. diam. by $10 \mathrm{ft}$. stroke driving a 30 -ft. flywheel through overhead beams. At 34 r.p.m. it developed 1,400 h.p. The machinery in the Hall was coupled to the engine by means of shafting and gearing beneath the floor. Original and independent in all his views, Corliss was generous as an employer and upright and outspoken as a public man. The sketch of his life in Mechanical Engineering is accompanied by a good photograph of him.

\section{Seeing Sound at the Chicago Exhibition}

THE exhibits of the Bell Telephone Co. at the Chicago Exhibition are of considerable interest. By means of a rotating mirror, beams of light are successively picked up from a small mirror on the receiver and flashed on a screen where they can be seen by a large audience. The speed of the mirror is regulated so as to give the best effect for sound and music. Typical speech sounds are listened to and at the same time their wave form is shown on the screen. High-pitched sounds show waves close together, and loud sounds result in waves of great height. Filters of various types are inserted and their effect in cutting out certain frequencies are both seen and heard. In the Bell Laboratories Record for August a full account is given by Mr. R. F. Mallina of these exhibits. A photograph is shown of the combined signal produced when twelve telegraph messages are transmitted simultaneously along a wire. Visitors to the exhibit can listen to the curious medley of musical sounds produced in the loud speaker. The combined sound gives no hint of what the messages are. When the complex current goes into the terminal apparatus the twelve different messages are all duly sorted out. Of particular interest was the separation of the rectangular pulses of direct current which operate teletype instruments from the corresponding high-frequency impulses caused by the combination of the carrier wave with the signal wave. The apparatus should prove useful in lecture rooms when it is necessary to explain the characteristics of various vibratory phenomena.

\section{Roofs made of Sheet Steel}

A NOVEL application of electric are welding has recently been begun in the United States. Roofs are made of long strips of sheet steel which are assembled and welded on the ground and then hung up between the top and bottom of the roof. The shape in which they hang is approximately that of a catenary and they are welded together. In the Electrical Review of August 25 a description is given of the 'selfsupporting' roofs erected on four huge grain elevators at Albany, Now York. These roofs are watertight and have no columns or stanchions to support them. Maximum storage capacity is thus obtained. Each roof measures $288 \mathrm{ft}$. wide with a total span of $140 \mathrm{ft}$. and is composed of 76 steel sheets $140 \mathrm{ft}$. in length and 50 in. wide. The lower support of the roof starts approximately $22 \mathrm{ft}$. above ground level and extends upward at an angle of $30^{\circ}-40^{\circ}$. Both the top and bottom supports were constructed at an angle to conform with the slope of the roof. By welding in various ways, expansion and contraction troubles are avoided. Small expansion joints were welded at suitable places over the longitudinal spans so as to allow free expansion for the roof. On completion, the roofs were given two coats of red lead and one of aluminium paint. With eight operators the speed of welding averaged $50 \mathrm{ft}$. per hour. More than 400 tons of sheet steel of No. 12 gauge were used.

\section{Increased Safety for Lift Passengers}

LIFTs for passenger service are being increasingly adopted in our larger cities. This is partly due to the erection of buildings of greater height in centralised positions. Anything therefore which adds to the safety and convenience of these devices is of importance. In the Osram General Electric Company's Bulletin for June, a description is given of a new device which ensures the safety of passengers from being struck by sliding doors whether they are operated by electric or pneumatic means. A beam of light is focused across the lift car entrance on to a photo-cell. Passengers entering or leaving the lift must of necessity interrupt this light beam. The effect of breaking the beam ensures either that the doors remain in the open position or, if they have started to close, that they will open again. All the time the beam of light is broken it is impossible to close the doors to the lift. The whole of the neces. sary apparatus can be fitted on the lift car and thus only one unit per lift is necessary. A unit comprises an adjustable projector arranged to focus light on a self-contained photo-cell set which operates relays in the motor room connected with the power doors. Structural alteration to standard types of lifts is not involved.

\section{Pulverised Fuel for Marine Boilers}

Authough use of pulverised fuel has made great progress in steam boilers on land, similar results have not been achieved in marine boilers for various reasons. One of these is the great size of the combustion chamber hitherto found necessary. The rate of 